\title{
COMPARATIVE ASSESSMENT OF RETENTIVE CHARACTERISTICS OF NYLON CAP VERSUS RETENTION.SIL IN BALL-RETAINED MANDIBULAR IMPLANT OVERDENTURES. A RANDOMIZED CLINICAL TRIAL
}

\author{
Reham B. Osman* and Mohamed Abdel Hakim Abdel Aal**
}

\begin{abstract}
PURPOSE: The purpose of this study was to clinically evaluate retentive characteristics of Retentive.Sil 600 attachment system and to compare it to that of Nylon cap in ball- retained mandibular implant overdentures.

Materials and Methods : Fourteen completely edentulous patients were included for this trial; seven patients /group following strict inclusion and exclusion criteria. The participants were randomly allocated to receive either nylon cap (control group) or Retention.Sil (intervention group) on ball abutments to retain 2-midsymphseal mandibular implant overdentures. Retention values of both attachment systems were evaluated in Newtons $(\mathrm{N})$, at baseline during time of denture insertion and thereafter at 3, 6, 9 and 12 months follow-up periods. Further the effect of time on retentive characteristics of both attachment systems was evaluated. The data was tabulated and statistically analysed using SPSS software.
\end{abstract}

Results: Nylon cap showed significantly higher mean retention values compared to Retention. Sil group at each of the observation periods $\mathrm{P} \leq 0.05$. In nylon caps group, there was a significant, gradual increase in retention values by time except at 6 and 9 months follow-up periods where the increase was non-significant. In Retention.Sil 600 group, retention gradually decreased by time. This decrease was statistically significant $(\mathrm{P}=0.00)$.

Conclusions: Within the limitations of this study, it can be concluded that retentive characteristics of any given attachment system is changeable overtime. Retention. Sil could be attachment of choice for retaining mandibular overdentures if reduced denture retention is required in cases with poor manual dexterity or temporarily for replacement of nylon caps of stud attachments when subjected to wear. Gradual decrease in retention of Retention.Sil over time merits further investigation to evaluate the durability of the material over extended follow-up periods.

* Lecturer, Faculty of Dentistry, Cairo University, Department of Prosthodontics

** Lecturer, Faculty of Oral and Dental Medicine, Beni-Suef University, Department of Removable Prosthodontics 


\section{INTRODUCTION}

Implant overdentures have successfully been used for the rehabilitation of completely edentulous patients. ${ }^{1}$ They are considered as an optimal alternative, standard of care especially for unsatisfied conventional complete denture wearers complaining from ill-fitting and non-retentive dentures.,3

Implant Overdentures (IODs) provide improved retention, support and stability through the use of various attachment systems that are currently available in the market. ${ }^{4}$ The wide variety of attachment systems include bar, ball, locator, magnets and telescopes. ${ }^{5}$ Ideally the attachment system should allow for adequate retention under long-term function. A direct relation exists between the retention and the stability of the prosthesis and the patients' satisfaction. Other factors that influence the attachment selection include chewing efficiency and comfort, phonetics and esthetics. ${ }^{6}$

Recently available, are silicone materials especially developed to be used as matrices known as polyvinyl siloxane (PVS) attachments. Examples of such attachments are Shore hardness (SH) and Retention.Sil systems. Similar to elastic impression materials, the fluid material is dispensed from a cartridge into the relieved intaglio surface of overdenture and onto the abutment surface. This is followed by a waiting period till the complete curing of the material. The process of material application is finalized by finishing and polishing using specially provided tools. ${ }^{7,8}$ Being more elastic, they allow for ease of insertion and removal of prosthesis. Furthermore, the manufacturers claim atraumatic and even stress distribution to the supporting structures with high chewing comfort because of the material flexibility. ${ }^{9}$ The reduced ability of advanced age patients to adapt to new complete dentures because of their reduced or diminished neuroplasticity can be easily addressed with this type of attachments. ${ }^{10}$ The economical advantage of chair-side pick up of such attachments also cannot be disregarded. It is further claimed that the retentive force of such attachments is constant over time. ${ }^{7}$ However, scientific clinical data evaluating the retention force of such attachments are scarce with only in-vitro studies available in the literature not fully simulating the complex oral environment.

Therefore, the aim of this randomized clinical trial was to evaluate the retentive characteristics of Retentive.Sil 600 (PVS) attachment system and to compare it to that of ball attachment in 2midsymphseal mandibular implant overdentures.

\section{MATERIALS AND METHODS}

\section{Patient Selection}

Screening took place from patients reporting to Faculty of Dentistry, Beni- Suef University, with functional problems with their complete dentures. Inclusion criteria were: completely edentulous patients with maladaptive dentures, adequate bone height and width to accommodate implants of 8,10 or $11.5 \mathrm{~mm}$ in length and $3.7,4.2$ or $4.7 \mathrm{~mm}$ in diameter. Exclusion criteria were: General systematic conditions that preclude implant surgical procedure, patients with severe oral hygiene deficiency or parafunctional activity such as bruxism and cases with reduced prosthetic vertical space that limits the placement of attachment system. Also patients using intravenous bisphosphonates or smoking more than 10 cigarettes/day were also excluded. The study was explained in details to all the included participants who provided a signed informed consent prior to the inclusion in the study.

\section{Study Design}

Fourteen participants were included in this trial. Each participant received a diagnostic complete maxillary and mandibular denture fabricated according to standardized prosthodontic protocol and wore it for approximately 8 weeks to ensure patients' adaptation to their new set of dentures. ${ }^{11}$ Randomization was performed in accordance with 
relevant items of the CONSORT checklist for randomized controlled trials using sequentially numbered, opaque, sealed envelopes containing either of the two interventions. In such a way, each participant had an equal chance of being included in either of the two groups. In the control group (n=7), the participants received ball attachments with their respective matrices picked up in the fitting surface of the dentures. While in the test group $(n=7)$, the overdentures were retained using Retention. Sil 600.

\section{Surgical Procedures}

Each participant received 2 mandibular interformanial implants (Legacy, Implant Direct LLC, Malibu Hills, CA 91301-USA). The length and the diameter of the implants were selected for each patient based on the available bone height and width. A surgical guide was used to ensure proper implant locations and angulations. The implants were placed using a flap protocol under local anesthesia (2\% Lidocaine with 1:100,000 epinephrine). A conventional loading protocol was followed. Following the implant surgeries, the fitting surface of the dentures were adequately relieved opposite to the placed implants and the dentures were lined with tissue conditioning material (visco-gel, Dentsply; UK) to ensure no load transmission to implants and avoid interference with the osseointegration. Then the patients were dismissed wearing their complete dentures.

\section{Prosthodontic Procedures}

Approximately 3 months following the first stage surgery, osseointegration of the implants was ensured using standardized long-cone, periapical radiographs. The implants were exposed, healing abutments was removed, and impression copings were attached to the implants and secondary impressions were done using Impregum impression material (Impregum, ESPE, Germany). Implant analogues were attached to copings and master casts were obtained on which diagnostic dentures were relined. An experienced laboratory technician performed all laboratory procedures. Respective matrices were picked-up in the finished dentures using a direct pick-up chair side technique. The attachment systems comprised ball abutments (patrices) of $2.5 \mathrm{~mm}$ diameter with collar height of $1.6 \mathrm{~mm}$ (Zimmer dental, USA) (Fig. 1).

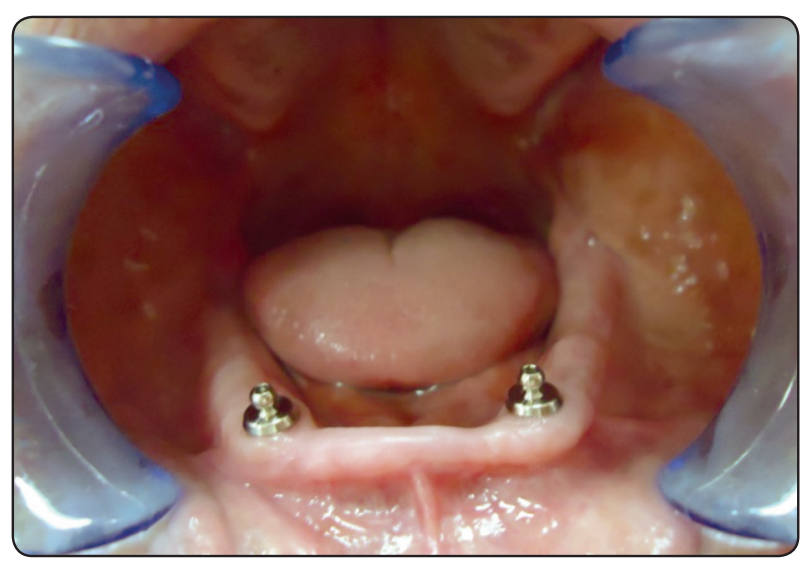

Fig (1) Ball abutments attached to implants 3 months after 1st stage surgery

In the control group, the corresponding matrices were made from polyoymethylene copolymer. The fitting surface of denture opposite to OT ball abutment was marked with an indelible pencil and was then copiously relieved. Further, two small holes were created in the lingual surface of the denture to allow for the escape of excess acrylic during the pick-up procedure. Blocking ring was then squeezed over the OT ball abutment to block out the undercuts and avoid interlocking of acarylic during pick-up procedure. Matrices were then snapped in their metal housings and seated over the ball abutment for the pick-up procedure. Self- cured acrylic resin was the mixed and placed in relieved fitting surface and then complete seating of denture was ensured in patient mouth (Fig 2).

In the test group, Retention.Sil 600 was used. First, the position of ball abutments was localized with the use of soft impression material. The marked 
positions of ball abutments were then ground out of the fitting surface of denture. The created recesses were then painted with primer liquid provided with Retention.Sil kit. After drying of the primer, Retention.Sil 600 paste was then applied and denture was fitted into its place over the OT ball attachment (Fig 3). Following the insertion of the dentures, the patients were educated on how to insert and remove their overdentures and were given full post-operative instructions. Recall appointments were scheduled at one-week, 4 weeks and then at 3 , 6 month and 1-year follow-up periods.

\section{Outcome Measures}

For both groups, retention of the implantsupported overdenture was measured using a Digital Forcemeter (Eagle: ELT 3000) at time of denture insertion and at 3, 6, 9 and 12 month follow-up period. The measuring unit of retention was obtained in Newtons (N). To ensure accurate, reproducible measurement, patients were instructed to sit in the dental chair, so that the occlusal plane was parallel to the floor to ensure that the dislodging force was perpendicular to mandibular occlusal plane. Each measurement was repeated three times, and the mean of those measurements was utilized for the statistical analysis and comparison between the groups. The force gauge was attached to hook fixed in the geometrical center of the denture for the retention measurements (Fig 4). The geometrical center was determined by a line joining the canine eminence and retromolar pad. Further, the changes in retention over time were evaluated and compared between both groups.

\section{Statistical Analysis}

Statistical analysis was then performed using a commercially available software program (SPSS 18; SPSS, Chicago, IL, USA). Data were expressed as means, standard deviation and standard error of means. Significance of the difference between

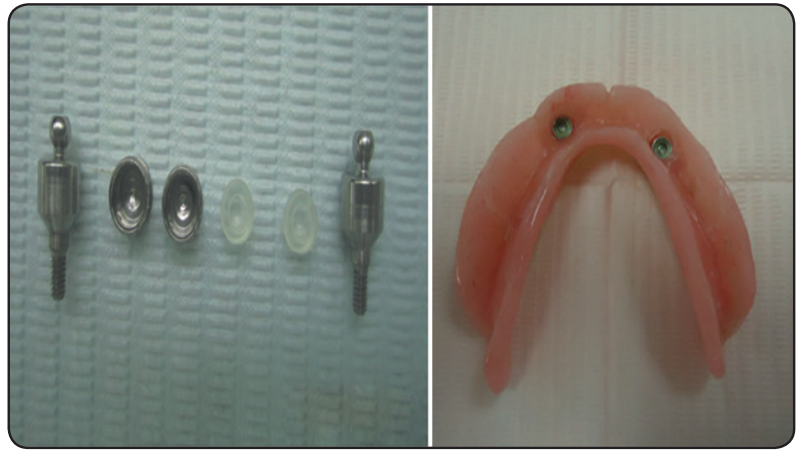

Fig. (2) Ball abutments with respective metal housings \& nylon caps

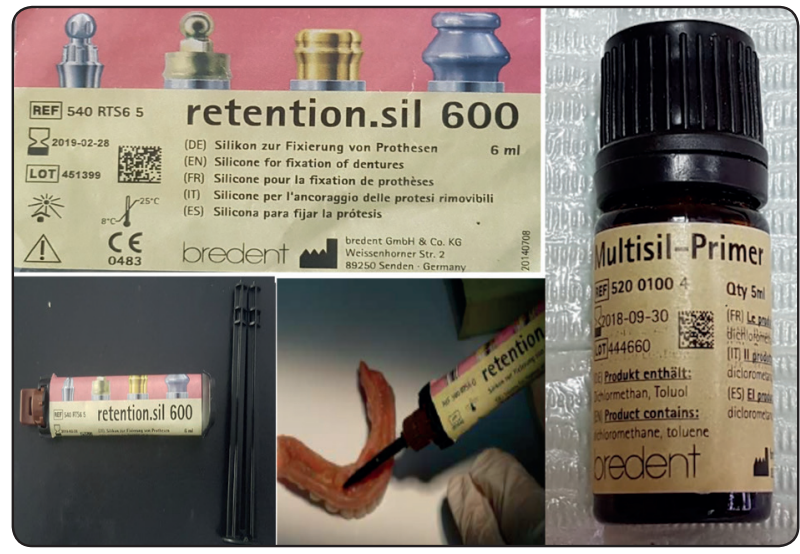

Fig. (3) The Retention.Sil $600 \mathrm{Kit}$ and its application in fitting surface of denture

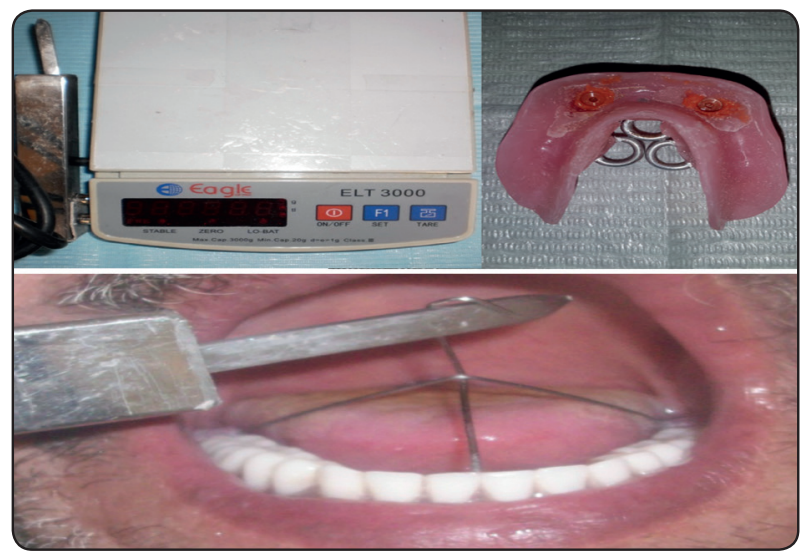

Fig. (4) Digital Forcemeter \& snaphooks attached to geometrical center of denture for retention measurement 
different observations within the same group was evaluated using one-way analysis of variance (ANOVA test), followed by Tukey's post hoc test when ANOVA revealed a significant difference. Both groups were compared using independent $t$ test. The level of significance was set at $\mathrm{P}<0.05$.

\section{RESULTS}

\section{Comparison between the groups:}

The statistical analysis revealed significantly higher mean retention values of Nylon caps when compared to Retention.Sil group at each of the observation periods (Table1)

\section{Comparison within the same group}

In nylon caps group, retention gradually increased by time. ANOVA test revealed that this increase by time was statistically significant $(\mathrm{p}=0.00)$. Tukey's post hoc test revealed no significant difference between values at 6 and 9 months (Tab1e 2, Fig.5)

In Retention.Sil 600 group, retention gradually decreased by time. ANOVA test revealed that this decrease was statistically significant $(\mathrm{p}=0.00)$. Tukey's post hoc test revealed a significant difference between each 2 observation times (Tab1e 2, Fig.5)

TABLE (1) Descriptive statistics of retention and Comparison between groups at each observation time (t-test)

\begin{tabular}{|c|c|c|c|c|c|c|c|c|c|c|}
\hline & \multirow[t]{2}{*}{ Groups } & \multirow[b]{2}{*}{ Mean } & \multirow[b]{2}{*}{ Std. Dev } & \multirow{2}{*}{$\begin{array}{l}\text { Std. } \\
\text { Error } \\
\text { Mean }\end{array}$} & \multicolumn{4}{|c|}{ Difference } & \multirow[t]{2}{*}{$\mathrm{t}$} & \multirow[t]{2}{*}{$\mathrm{p}$} \\
\hline & & & & & Mean & SE & C.I. lower & C.I. upper & & \\
\hline \multirow[t]{2}{*}{ At.insertion } & Nylon caps & 14.82 & .18 & .07 & \multirow[t]{2}{*}{4.32} & \multirow[t]{2}{*}{.08} & \multirow[t]{2}{*}{4.14} & \multirow[t]{2}{*}{4.51} & \multirow[t]{2}{*}{51.60} & \multirow[t]{2}{*}{$.00 *$} \\
\hline & Sil 600 & 10.50 & .13 & .05 & & & & & & \\
\hline \multirow[t]{2}{*}{ Three.months } & Nylon caps & 15.28 & .28 & .11 & \multirow[t]{2}{*}{5.47} & \multirow[t]{2}{*}{.12} & \multirow[t]{2}{*}{5.20} & \multirow[t]{2}{*}{5.73} & \multirow[t]{2}{*}{46.54} & \multirow[t]{2}{*}{$.00 *$} \\
\hline & Sil 600 & 9.82 & .13 & .05 & & & & & & \\
\hline \multirow[t]{2}{*}{ Six.months } & Nylon caps & 15.93 & .13 & .05 & \multirow[t]{2}{*}{8.29} & \multirow[t]{2}{*}{.07} & \multirow[t]{2}{*}{8.14} & \multirow[t]{2}{*}{8.43} & \multirow[t]{2}{*}{125.52} & \multirow[t]{2}{*}{$.00 *$} \\
\hline & Sil 600 & 7.65 & .12 & .05 & & & & & & \\
\hline \multirow[t]{2}{*}{ Nine.months } & Nylon caps & 16.08 & .19 & .07 & \multirow[t]{2}{*}{9.22} & \multirow[t]{2}{*}{.08} & \multirow[t]{2}{*}{9.04} & \multirow[t]{2}{*}{9.41} & \multirow[t]{2}{*}{111.11} & \multirow[t]{2}{*}{$.00 *$} \\
\hline & Sil 600 & 6.86 & .11 & .04 & & & & & & \\
\hline \multirow{2}{*}{$\begin{array}{l}\text { Twelve. } \\
\text { months }\end{array}$} & Nylon caps & 18.41 & .46 & .17 & \multirow[t]{2}{*}{12.42} & \multirow[t]{2}{*}{.18} & 11.99 & 12.85 & 67.21 & $.00 *$ \\
\hline & Sil 600 & 5.99 & .18 & .07 & & & & & & \\
\hline
\end{tabular}

Significance level $p \leq 0.05$, significant, $C . I=95 \%$ confidence interval 
TABLE (2) Effect of time on the retention characteristics within the same group (ANOVA test)

\begin{tabular}{|c|c|c|c|c|c|c|c|c|c|c|}
\hline & & \multirow{2}{*}{ Mean } & \multirow{2}{*}{$\begin{array}{l}\text { Std. } \\
\text { Dev }\end{array}$} & \multirow{2}{*}{$\begin{array}{l}\text { Std. } \\
\text { Error }\end{array}$} & \multicolumn{2}{|c|}{$\begin{array}{l}\text { 95\% Confidence Interval for } \\
\text { Mean }\end{array}$} & \multirow{2}{*}{ Min } & \multirow{2}{*}{ Max } & \multirow{2}{*}{$\mathrm{F}$} & \multirow{2}{*}{$\mathrm{P}$} \\
\hline & & & & & Lower Bound & Upper Bound & & & & \\
\hline \multirow{5}{*}{$\begin{array}{l}\text { Nylon. } \\
\text { caps }\end{array}$} & At insertion & $14.823^{\mathrm{d}}$ & .179 & .068 & 14.657 & 14.989 & 14.560 & 15.030 & \multirow{5}{*}{180.89} & \multirow{5}{*}{$.000 *$} \\
\hline & 3 months & $15.281^{\mathrm{c}}$ & .280 & .106 & 15.022 & 15.541 & 14.950 & 15.660 & & \\
\hline & 6 months & $15.934^{\mathrm{b}}$ & .127 & .048 & 15.817 & 16.052 & 15.780 & 16.140 & & \\
\hline & 9 months & $16.080^{\mathrm{b}}$ & .189 & .071 & 15.906 & 16.254 & 15.850 & 16.380 & & \\
\hline & 12 months & $18.410^{\mathrm{a}}$ & .457 & .173 & 17.988 & 18.832 & 17.860 & 18.850 & & \\
\hline \multirow{5}{*}{ Sil600 } & At insertion & $10.501^{\mathrm{a}}$ & .130 & .049 & 10.381 & 10.622 & 10.340 & 10.670 & \multirow{5}{*}{1405.63} & \multirow{5}{*}{$.000 *$} \\
\hline & 3 months & $9.816^{\mathrm{b}}$ & .134 & .051 & 9.692 & 9.940 & 9.680 & 10.040 & & \\
\hline & 6 months & $7.646^{c}$ & .120 & .045 & 7.535 & 7.757 & 7.450 & 7.780 & & \\
\hline & 9 months & $6.859^{\mathrm{d}}$ & .113 & .043 & 6.754 & 6.963 & 6.690 & 7.010 & & \\
\hline & 12 months & $5.989^{\mathrm{e}}$ & .175 & .066 & 5.827 & 6.150 & 5.780 & 6.250 & & \\
\hline
\end{tabular}

Significance level $p \leq 0.05$, * significant

Tukey's post hoc test: Within the same group, means sharing the same superscript letter are not significantly different

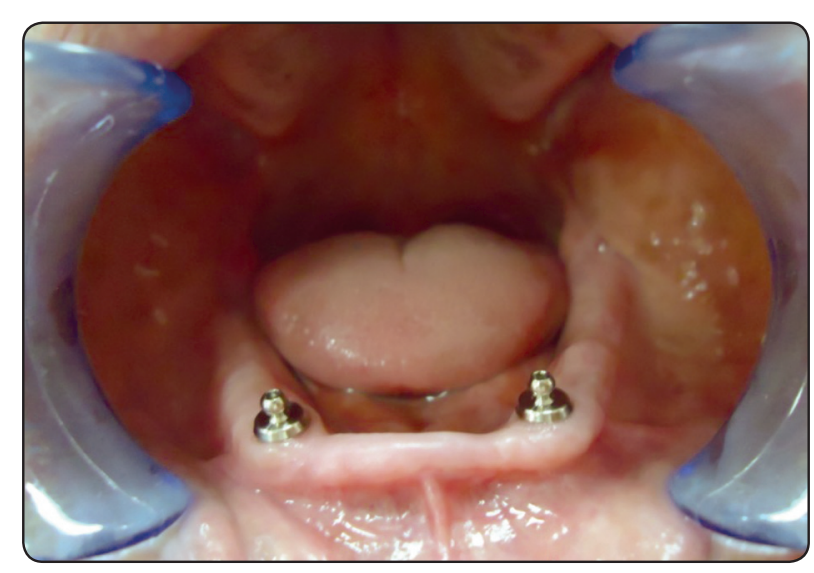

Fig. (5) Bar chart showing mean value of retention $(\mathrm{N})$ at each observation time in both groups

\section{DISCUSSION}

The aim of this randomized trial was to evaluate the retention characteristics of Retention. Sil 600-attachment system and compare it to that of ball attachment with nylon caps in case of 2-interformanial mandibular implant overdentures at the time of denture insertion and at 3, 6, 9 and 12 months follow-up period. The retention was significantly higher for ball attachment with nylon caps compared to Retention.Sil though values for both groups were still within the clinically accepted range. In-vitro investigations suggested 4 $\mathrm{N}$ as minimum retentive force expected of a single unsplinted attachment system. ${ }^{12,13}$

The simplicity of unsplinted attachment systems has made them widely used especially 
for mandibular implant overdentures. ${ }^{14}$ Ball and locator attachments are considered as gold standard for implant overdenture connection. Unsplinted attachments may not be optimal for frail and care dependent patients. With locator attachments, food residues can accumulate in the central depression of the patrix and inhibit the locking of the matrix, and also create a problem with the hygiene of prosthesis. Moreover, retention forces of the unsplinted attachments are often too high for elderly frail patients in the fourth phase of life. ${ }^{8}$

Reduced retention thus becomes a prerequisite for patients with poor manual dexterity, arthritis and age-dependent muscle weakness that may have difficulty inserting and removing the overdenture. ${ }^{9}$ Therefore to ensure adequate treatment planning and restorative success, the retentive characteristics of the attachment system should match the physical conditions and needs of the patients..$^{15}$ In such context, the newly introduced PVS attachments with reduced retention values are will situated for geriatric patients with limited manual dexterity as well as cases of immediate loading to ensure minimal stress transfer to osseointegrating implants. ${ }^{15}$

Though it is suggested that the retentive qualities of any retentive system should be relatively constant over a proposed period of time, this is usually not case in real clinical situations. ${ }^{12}$ Most of in-vitro studies apply only centric loading which reduces the artificial aging relative to the eccentric loading with subsequent reduction in wear of the attachments and relatively constant retention values.

The interplay of various factors such as chemical, physical properties of the attachment material, composition and type of patients' saliva all influences the resultant amount of retention. The technique of application of Retention.Sil in fitting surface of denture though simple might be a contributing factor for observed reduction in retention over time. Dispensing of fluid Retention. Sil into the relieved surface of denture entails the possibility of incorporating air bubbles and inconsistencies that reduce the retention and the durability of the attachment system ${ }^{8}$ Similarly, Schweyen et al. $2018^{8}$, reported $66 \%$ loss of retention of high initial retention of prefabricated polyvinylsiloxane (PPVS) attachment.

The observed increase in the retentive force of two-ball attachment system is consistent with what is reported in the literature. Bayer et al., $2009^{16}$ reported an initial increase in the retention force of IB group attachments at the beginning of the wear simulation when subjected to 0-2000 insertion/ separation cycles, which is equivalent to 1.5 year of function clinically. In the later study described, IB attachment consists of a ball abutment with a plastic retentive insert of female part. The initial median retention reported was $15.7 \mathrm{~N}$ with an initial increase in retention value of $2 \mathrm{~N}$, which is very close to values reported in this study. The initial increase in retention force observed may be related to increased mechanical adaptation of attachment system under cyclic loading resulting from the abrasion and material degradation of the retentive components. ${ }^{17}$ Initially this will result in reduced sliding of attachment components on top of each other and increased wear products with the resultant increase in retention values recorded. ${ }^{6,17}$

Future clinical research should evaluate hygiene aspects of PVS attachments. PVS used, as a soft liner for removable complete and partial dentures should be regularly changed because of bacterial colonization, which takes place intra-orally within a few month period. Whether the same concept will apply for PVS attachments and necessitate the frequent replacement of the matrices due to smell and/or appearance merits further investigations. ${ }^{18}$ The frequency of matrix PVS change over extended follow-up periods should also be evaluated to enable proper assessment of prosthodontic burden associated with the use of PVS attachments as overdenture matrices. 


\section{CONCLUSIONS}

Within the limitations of this study, it can be concluded that retentive characteristics of any given attachment system is changeable overtime. Retention.Sil could be attachment of choice for retaining mandibular overdentures if reduced denture retention is required in cases with poor manual dexterity or temporarily for replacement of nylon caps of stud attachments when subjected to wear. Gradual decrease in retention of Retention.Sil over time merits further investigation to evaluate the durability of the material over longer followup periods. The hygiene aspects of Retention.Sil attachment should as well be investigated.

\section{REFERENCES}

1. Davis DM. Implant-stabilized overdentures. Dent Update 1997; 24:106-109.

2. Sadowsky SJ. Mandibular implant-retained overdentures: a literature review. The Journal of prosthetic dentistry 2001;86: 468-473.

3. Doundoulakis JH, Eckert SE, Lindquist CC, et al. The implant-supported overdenture as an alternative to the complete mandibular denture. J Am Dent Assoc 2003; 134:1455-1458.

4. Mensor MJ Jr. Attachment fiation for overdentures. Part I. J Prosthet Dent. 1977; 37:366-372.

5. Kim HY, Lee JY, Shin SW, Bryant SR. Attachment systems for mandibular implant overdentures: A systematic review. J Adv Prosthodont 2012; 4:197-203.

6. Alsabeeha N, Payne A, Swain MV. Attachment systems for mandibular two implant overdentures: A review of the invitro investigations on retention and wear features. Int $\mathbf{J}$ Prosthodont 2009; 22:429-440.

7. Schweyen R, Beuer F, Arnold C, Hey J. Retentive characteristics of a vinylpolysiloxane overdenture attachment system. Clin Oral Invest. 2015; 19:947-953.
8. R Schweyen, C Arnold, J. M. Setz, J. Hey. Retentive characteristics of individual and prefabricated polyvinylsiloxane overdenture attachments: alternative treatment options for geriatric patients. Clin Oral Invest. 2018; https://doi.org/10.1007/s00784-018-2568-x.

9. Chung K-H, Chung C-Y, Cagna DR, Cronin RJ Jr. Retention Characteristics of Attachment Systems for Implant Overdentures. J Prosthodont 2004; 13:221-226.

10. Thompson GW, Kriesel PS. The impact of demographics of aging and the edentulous condition on dental care service. J Prosthet Dent. 1998; 79-56-59.

11. Zarb GA. The edentulous predicament. In Zarb GA, Bolender CL, Eckert SE, Jacobs RF, Fenton AH, MerickeStern R, eds. Prosthodontic treatment for edentulous patients: Complete dentures and implant supported prostheses. 12 ed. St Louis: Mosby 2004, 3-5.

12. Lehmann KM, Amim FV. Studies on the retention forces on snap on attachments. Quintessence Dent Technol 1978;7: 45-48.

13. Stewart BL, Edward RO. Retention and wear of precisiontype attachments. J Prosthet Dent 1983; 49: 28-34.

14. Preiskel H. Overdentures made easy: A guide to implant and root supported prostheses. London: Quentessence; 1996.

15. Müller F, Duvernay E, Loup A, Vazquez L, Hermann FR, Schimmel M. Implant-supported mandibular overdentures in very old adults- a randomized controlled trial. J Dent Res 2013; 92: 154-162.

16. Bayer S, Steinheuser D, Grüner M, Keilig L, Enkling N, Stark H, Mues S. Comparative study of four retentive anchor systems for implant supported overdentures retention force changes. Gerodontolog 2009; 26: 268-272.

17. Botega DM, Mesquita MF, Henriques GE, Vaz LG. Retention force and fatigue strength of overdenture attachment systems. J Oral Rehabil 2004; 31: 884-889.

18. Pavan S, dos Santos PH, Filho JN, Spolidorio DM. Colonisation of soft lining materials by microorganisms. Gerodontol 2010; 27:211-216. 